Bulletin UASVM Food Science and Technology 70(2)/2013, 118-123

ISSN-L 2344-2344; Print ISSN 2344-2344; Electronic ISSN 2344-5300

\title{
Revaluation of Waste Yeast from Beer Production
}

\section{Nicoleta SURUCEANU, Sonia SOCACI, Teodora COLDEA, Elena MUDURA*}

Faculty of Food Science and Technology, University of Agricultural Science and Veterinary Medicine, Manastur 3-5, Cluj-Napoca, Romania

"elena.mudura@usamvcluj.ro

\begin{abstract}
Brewing yeast is an important waste product from beer production. The revaluation of slurry yeast mainly consists of separation of vitamins and important nitrogen compounds. The hops compounds, one of the most important raw materials in beer technology are removed beforehand valorification. The prenylflavonoids compounds from hops are important bioactive compounds that can be revaluation with proper technology. The aim of this study is revaluation of prenylflavonoids from waste yeast into dietary supplement and identification and quantification of xanthohumol by HPLC method. Waste yeast from brewery pilot plant of USAMV Cluj Napoca it was dried by atomization and xanthohumol content of powder was analyzed by HPLC method. For quantification a calibration curve it was used. The process of drying by atomisation lead to a powder product. It was used maltodextrin powder for stabilisation. The final product it was encapsulated. The xanthohumol content of powdered yeast it was $1.89 \mu \mathrm{g} / \mathrm{g}$. In conclusion the slurry yeast from beer production it is an important source of prenylflavonoids compounds for dietary intake.
\end{abstract}

Keywords: xanthohumol, brewing, waste yeast, dietary supplement

\section{INTRODUCTION}

Hops are used in brewing industry for the flavor, color and bitter taste of beer. This plant is very rich in prenylflavonoids, a set of compounds like xanthohumol, isoxanthohumol, 8prenilnaringenin which have a very important biological active role for the health of humans (Gerhauser, 2005; Possemiers at al., 2006).

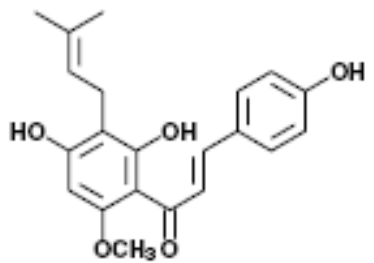

Xantohumol

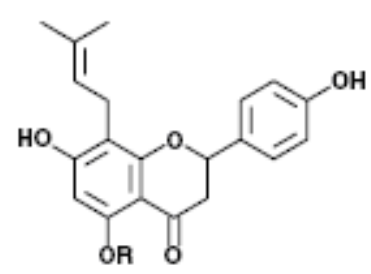

Izoxantohumol $\mathrm{R}=-\mathrm{CH} 3$

\section{8-Prenilnaringenina $\mathrm{R}=-\mathrm{H}$}

Fig. 1 The important prenilflavonoids from hops (Humulus lupulus L.)

An extremely valued compound is xanthohumol, especially in medicine and pharmaceutical industry. It has anticancer activity, anti-lipoperoxidative, anti-inflammatory and 
apoptotic effects. In hops, xanthohumol is present in small quantity of $1.1 \%$, but the problem appears in the brewing process when boiling the must with the hops. In this stage, xanthohumol isomerizes into isoxanthohumol. Isoxanthohumol is not as active like xanthohumol, so for bioactive food supplements is important to avoid this reaction.

The prenylflavonoid compounds come originally from the hop that is used in brewing technology. The spectra of the prenylflavonoidic compounds which are found in beer depend on the quality and quantity of hop, the wort composition and boiling process parameters. During the alcoholic fermentation of the wort and beer conditioning, the concentration of prenylflavonoidic substances is reduced especially because of the absorption of these compounds on the yeast surface. The final quantity depends on the characteristics of the raw materials, the extraction used technology and the capacity of the installation.

The aim of this research is to obtain a dietary supplement from the brewer's yeast used in the process of fermentation after boiling the wort with the hops. This method actually supports the fact that the yeast adsorb on it cell the xanthohumol. The method used in order to obtain powdered yeast is atomization; before that, the yeast was incorporated in maltodextrine in order to protect it. At the end, the powdered yeast was encapsulated and presented as food supplement.

Identification and quantification of izoxanthohumol and xanthohumol are related to the determination of these compounds in the finished product, not during the whole beer brewing process. Stevens et al. studied the fate of xanthohumol and izoxanthohumolului during the brewing process. Due to the partial inhibition of the isomerization process along brewing, dark beers are xanthohumol-enriched hop products.

Dark malt contains compounds responsible for the partial inhibition of xanthohumol thermal isomerisation during wort boiling. Reaction between xanthohumol and coloured substances from dark malt, melanoidins, changes chemical properties of xanthohumol. This leads to an inhibition of xanthohumol isomerisation during wort boiling (Magalhaes, 2011).

Dietary supplements containing brewer's yeast often contain non-living, dried yeast. People use brewer's yeast for medicinal puropses. Brewer's yeast is used for diarrhea, the common cold and other upper respiratory tract infections, influenza, swine flu, loss of appetite, acne, premenstrual syndrome (PMS) and type 2 diabetes. It has also been used as a source of B vitamins, chromium, and protein.

\section{MATERIALS AND METHODS}

The atomization procedure was applied to brewing's yeast Saccharomyces cerevisiae used in beer production. The yeast it was subjected to freeze-drying process to test how effective this method could be used to obtain a fine powder. The slurry yeast had been obtained using classical brewing technology. Production trials were performed in brewery pilot plant from USAMV Cluj-Napoca. The technological parameters were adapted and monitored during the mashing process. Whole mash from pale and dark malt it was used for mashing and infusion regime it was adapted. The original extract of wort it was adjusted at $12^{\circ} \mathrm{P}$. The wort it was boiled with hops for 90 minute. Xanthohumol isomerises during boiling and it forms the compound isoxanthohumol. Isoxanthohumol activity does not look as good as that of xanthohumol. High levels of xanthohumol in beer could be achieved by a combination of high hopping rates, very late hopping and the use of repitched yeast.

The hoping rate it was increase from 8 to $16 \mathrm{mg}$ iso alfa acid/hl for a better solubilisation. After cooling, the wort was pitched with yeast Saccharomyces cerevisiae at $10 \times$ 
$10^{6}$ yeast cells $/ \mathrm{ml}$ wort. The wort was allowed to ferment for 7 days after which the yeast was harvest beer and mixed with $100 \mathrm{~g} / 1$ maltodextrin. The resulting mixture was subjected to atomization. Process time of atomization was for 90 minutes (Figure 2).

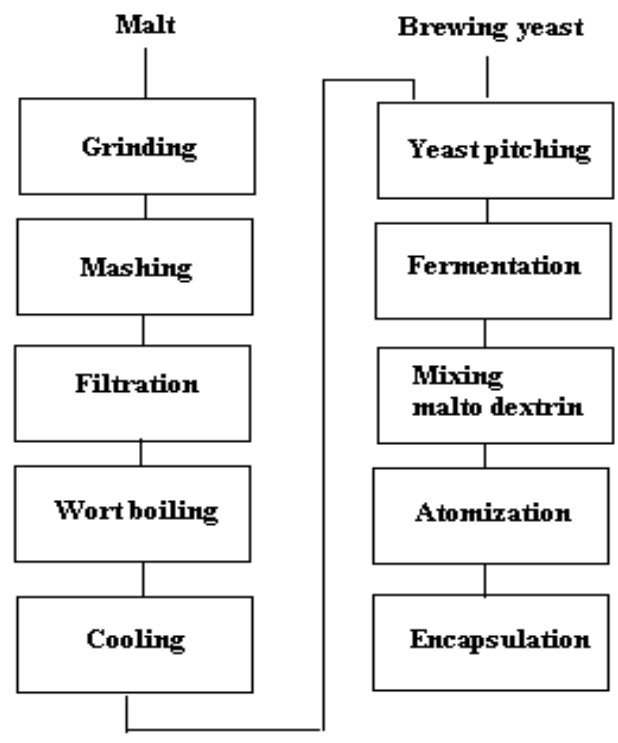

Fig. 2. The flow chart for encapsulated yeast production

Sample preparation: methanol extract. A sample of $10 \mathrm{~g}$ atomized yeast is taken in a $250 \mathrm{ml}$ flask with ground glass stopper and subjected to extraction with methanol: diethyl ether: $0.1 \mathrm{~N}$ hydrochloric acid $(20 \mathrm{ml}: 100 \mathrm{ml}: 40 \mathrm{ml})$; the flask coppered and stirred for 40 minutes on a platform shaker. Allow standing for 10 minutes, then $5 \mathrm{ml}$ of supernatant is transferred into $50 \mathrm{ml}$ flask and bring to volume with HPLC grade methanol. The sample is shaking and filtering through $0.45 \mu \mathrm{m}$ filters.

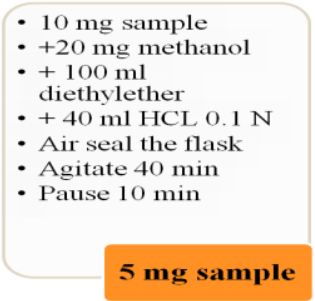

\section{Graduated} flask of $50 \mathrm{ml}$

- Dilute up to the mark with methanol

- Agitate

- Microfiltrate

(organic filter 0.45

$\mu \mathrm{m})$

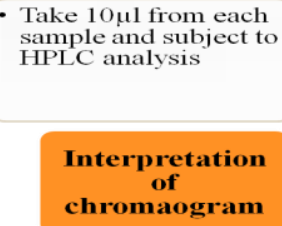

Sample preparation: aqueous extract. The aqueous extract it was prepared as methanol extract by replacing the organic solvents with the same amount of water.

Preparation of standard solution for external calibration. Accurately weight $1.3 \mathrm{mg}$ of pure xanthohumol was transferred into $5 \mathrm{ml}$ graduated flask and made up volume with methanol at $20^{\circ} \mathrm{C}$ for preparation of stock solution. From stock solution it were prepared dilution to 10 $\mu \mathrm{g} / \mathrm{ml}, 5 \mu \mathrm{g} / \mathrm{ml}, 2.5 \mu \mathrm{g} / \mathrm{ml}, 1 \mu \mathrm{g} / \mathrm{ml}$ and $0.5 \mu \mathrm{g} / \mathrm{ml}$. Pure xanthohumol was purcesed from Alexis Biochemicals, San Diego, USA.

Qualitative and quantitative determination of xanthohumol from yeast it was performed using reverse phase HPLC techniques using a modification of EBC method for iso alpha acids determination (Stevens, 1999).

- Instrument: HPLC Schimadzu 1100 Series 
- $\quad$ Column: RoSIL - C18 250×4.6 mm, $5.0 \mu \mathrm{m}$ from RSL - Alltech - Europe

- Mobile phase: A: methanol;

B: methanol : water : orthophosphoric acid $=750: 240: 10(\mathrm{v} / \mathrm{v} / \mathrm{v})$

- $\quad$ Flow rate: $1 \mathrm{ml} / \mathrm{min}$

- Temperature: $35^{\circ} \mathrm{C}$

Elution program for HPLC-UV analysis of xanthohumol

Tab. 1

\begin{tabular}{|l|l|l|l|}
\hline \multicolumn{1}{|c|}{ Time } & \multicolumn{1}{|c|}{ Unity } & \multicolumn{1}{c|}{ Command } & \multicolumn{1}{c|}{ Value } \\
\hline $00: 01$ & Pump B & Concentration pump B & $38 \%$ \\
\hline $00: 01$ & Detector SPD-10 A VP & Wavelength & $270 \mathrm{~nm}$ \\
\hline $3: 70$ & Pump B & Concentration pump B & $70 \%$ \\
\hline $3: 71$ & Pump B & Concentration pump B & $38 \%$ \\
\hline $3: 71$ & Detector SPD-10 A VP & Wavelength & $314 \mathrm{~nm}$ \\
\hline 4:20 & Controller & Stop & \\
\hline
\end{tabular}

\section{RESULTS AND DISCUSSIONS}

The identification and quantification of xanthohumol it was performed with calibration curve. Identification of xanthohumol was done by retention time of standard solution (Figure 3). Retention time for xanthohumol is $\mathrm{t}_{\mathrm{Rxanthohumol}}=1.36 \mathrm{~min}$.
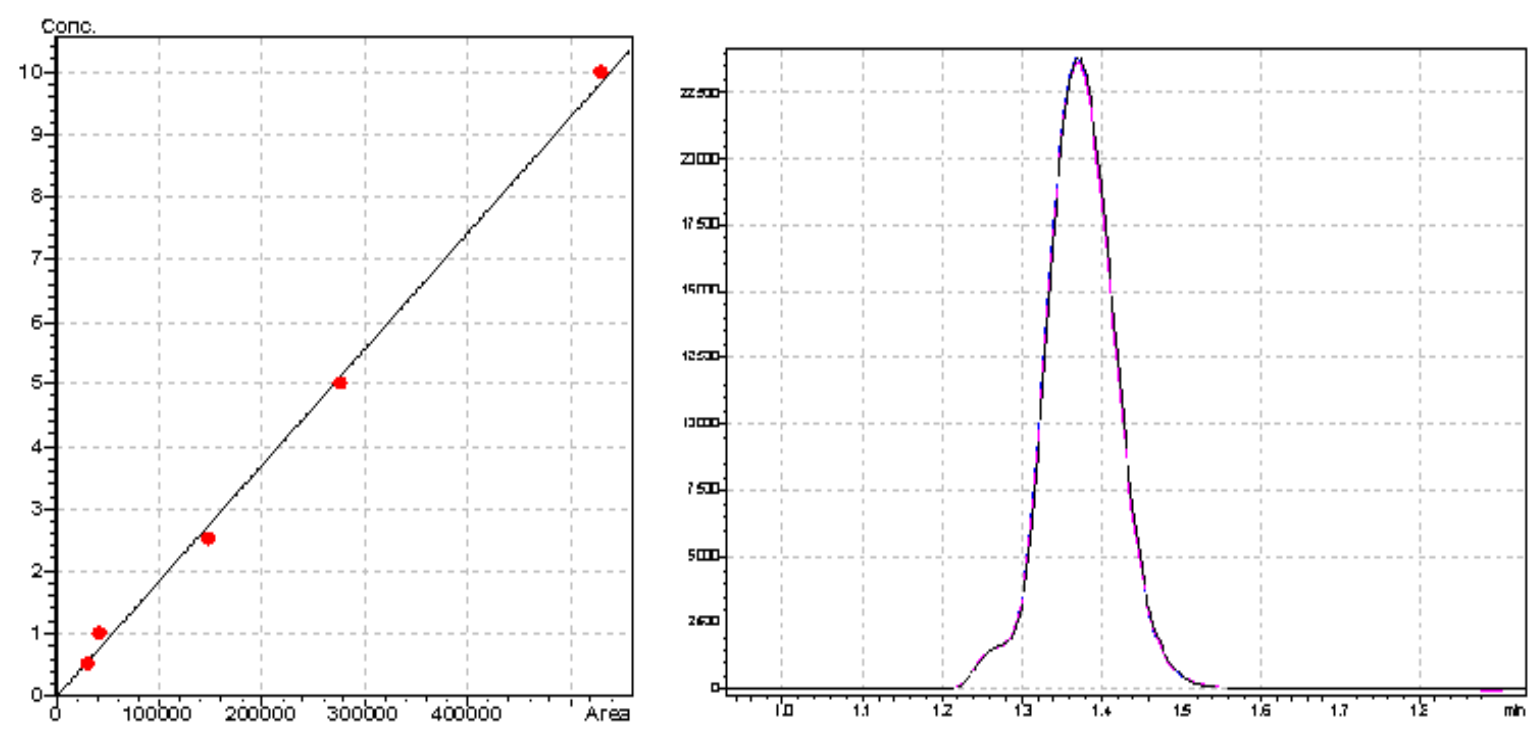

Fig. 3. The calibration curve of xanthohumol and xanthohumol standard chromatogram

In atomized yeast, it was found a small amount of xanthohumol, respectively 1.84-1.89 $\mu \mathrm{g} / \mathrm{ml}$ for methanol extract samples and $0.76 \mu \mathrm{g} / \mathrm{ml}$ for aqueous extract samples (Fig. 4). As seen, the aqueous extract has less half the amount identified in the methanol extract. This observation is important for getting a dietary supplement. 


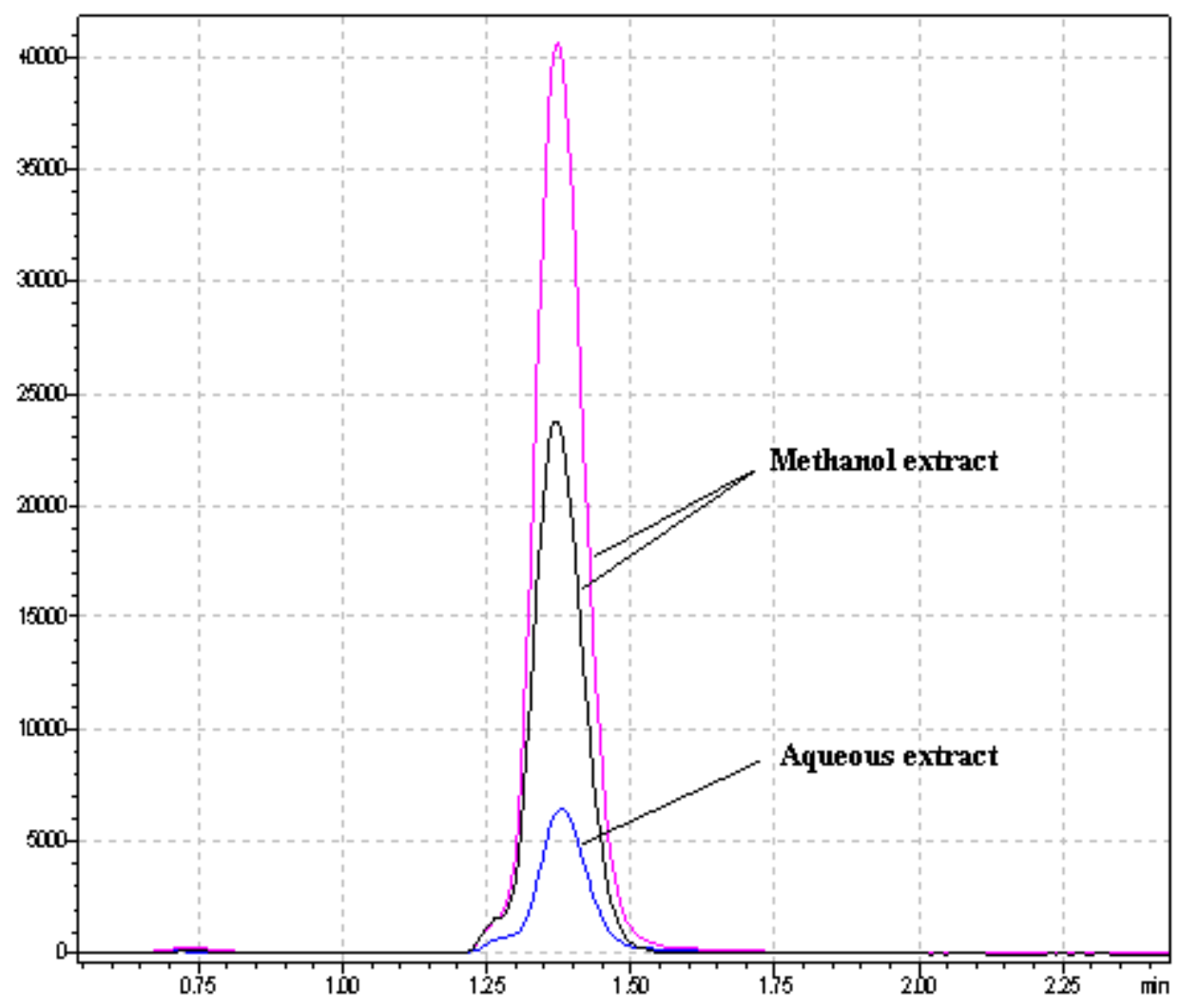

Fig. 4. The chromatogram of yeast samples (methanol and aqueous extract)

The results show that the powder of brewing yeast contains xanthohumol, but not as much as we are expected. Further researches have to investigate the influence of atomization process on fate of xanthohumol and stability of food supplement during the time.

\section{CONCLUSION}

This work confirms that brewing yeast Saccharomyces cerevisiae has the ability to retain xanthohumol in its cellular walls. The quantity depends on the initial concentration of xanthohumol in wort and the pitching rate.

Xanthohumol is highly valued in many pharmaceutical research, medicine and food industry. A food supplement with brewing yeast would provide a significant amount of xanthohumol to dietary intake.

The evaluations of xanthohumol in methanol extract and than in aqueous extract demonstrate the bioavailability of this compound for human body.

This work is actually a reference to the following research studies that will focus on exploring the revaluation of brewing yeast in food supplements as a source of prenylflavonoid compounds. 


\section{REFERENCES}

1. Gerhauser C, Alt AP, Klimo K. (2002). Isolation and potential cancer chemopreventive activities of phenolic compounds of beer'. Phytochem 1:369-377.

2. Gerhaeuser, C., Alt, A., Heiss, E., Gamal-Eldeen, A., Klimo, K., Knauft, J., Neumann, I., Scherf, H.R., Frank, N., Bartsch, H., Becker, H.(2002). Cancer chemopreventive activity of xanthohumol, a natural product derived from hop. Mol. Cancer Ther. 1: 959-969.

3. Magalhaes Paulo J., Lu'1s F. Guido, Jos'e M. Cruz, Aquiles A. Barros. (2006). Analysis of xanthohumol and isoxanthohumol in different hop products by liquid chromatography-diode array detection-electrospray, ionization tandem mass spectrometry. Journal of Chromatography A. 1150: 295301

4. Magalhães Paulo J., Aurora B. Carvalho1, Luís M. Gonçalves1, João G. Pacheco1, Luís F. Guido1, Tomáš Brányik, Pedro G. Rodrigues, Gabriela Kuncová, Pavel Dostálek and Aquiles A. Barros. (2011). The Impact of Xanthohumol on a Brewing Yeast's Viability, Vitality and Metabolite Formation. J. Inst. Brew. 117(3): 368-376.

5 . Magalhães, . P. J., S. M. Almeida, A. M. Carvalho, L. M. Gonçalves, J. G. Pacheco, J. M. Cruz, L. F. Guido and A. A. Barros.(2011). Influence of malt on the xanthohumol and isoxanthohumol behavior in pale and dark beers: A micro-scale approach. Food Research International. 44: 351-3592. 6.

Miranda, C.L., Stevens, J.F., Helmrich, A., Henderson, M.C., Rodriguez, R.J., Yang, Y.H., Deinzer, M.L., Barnes, D.W., Buhler, D.R. (1999). Antiproliferative and cytotoxic effects of prenylated flavonoids from hops (Humulus lupulus) in human cancer cell lines. Food Chem. Toxicol. 37: 271-285.

7. Miranda C.L, Stevens JF, Ivanov V. (2000). Antioxidant and prooxidant actions of prenylated and nonprenylated chalcones and flavanones in vitro. J Agric Food Chem. 48: 3876-3884.

8. Stevens, J. F., Taylor, A. W. and Deinzer, M. L. (1999). Quantitative analysis of xanthohumol and related prenylflavonoids in hops and beer by liquid chromatography - tandem mass spectrometry. J. Chromatogr. A. 832: 97-107.

9. Stevens, J. F., Taylor, A. W., Clawson, J. E. and Deinzer, M. L. (1999). Fate of xanthohumol and related prenylflavonoids from hops to beer. J. Agric. Food Chem.47: 2421-2428 